\title{
PLUTONISMO GRANITICO NOS ARREDORES DO SÍTIO DOS NUNES, PERNAMBUCO, E SEU SIGNIFICADO NO CONTEXTO DA GRANITIZAÇÃO BRASILIANA DO NORDESTE
}

\author{
EDILTON J. DOS SANTOS* e MARIA LÚGIA VASCONCELOS** \\ Granitic magmas might be characterized as the sweat that oozes out from \\ the body of mother earth during the convulsions of orogeny \\ Eskola, 1932
}

\begin{abstract}
The granites of the Sítio dos Nunes region were emplaced in a precambrian metamorphic belt of Brazilian age (570 to $900 \mathrm{~m} . \mathrm{y}$.), developed along the north margin of the Itaíba Massif - a huge mass of cratogenic affinity situated in the Caririan space, northeast Brazil. They constitute disharmonious to semidisharmonious biotite granite bodies of different sizes, roughly rounded in form. The Sítio dos Nunes massif shows both concordant and faulted contacts and displays internal structures fairly parallel to its boundaries; conspicuous schistose, gneissic, amphibolitic, and calcareous enclaves exhibit a quite regular pattern, although vertical flow planes denote a certain degree of mechanical mobility of the granitic medium. Skarns and transitional facies of the granite are products of exo and endomorphic phenomena in the vicinity of the calcareous enclaves. The Fátima and São João dos Leites stocks cut abruptly the surrounding rocks, developing some contact metamorphic derivates and including displaced enclaves. Analysis of the geological setting and petrographic comparisons with granites of anatectic origin related to median and basement massifs demonstrate the existence of a granite series, in which the Sítio dos Nunes suite is the intrusive rheomorphic phase.
\end{abstract}

INTRODUÇÃo O maciço granítico do Sítio dos Nunes é um corpo com pouco mais de $150 \mathrm{~km}^{2}$ de área aflorante, situado nos arredores do distrito de mesmo nome, município de Flores, Pernambuco. Localizado durante o levantamento geológico da folha Arcoverde (efetuado para a SUDENE, DRN, Divisão de Geologia, em 1968), ele mereceu maior detalhe de estudo pelo fato de incluir numerosos enclaves de rochas calcárias, despertando interesse, não só do ponto de vista petrológico, como também pela mineralização em potencial que a associação poderia gerar. Este trabalho é o resultado do estudo petrológico efetuado nesse maciço e nos stocks de Fátima e de São João dos Leites, que lhe são consangüíneos (Fig. 1). Maciços similares ocorrem a nordeste dessa área, numa faixa de direção NE-SW, os quais não foram estudados no presente trabalho.

O AMBIENTE DE FORMAÇÃO E A TIPOLOGIA GRANÍTICA REGIONAL Os granitos dos arredores do Sítio dos Nunes situam-se na região de dobramentos caririanos (Almcida et al., 1968), a qual se distribui na margem setentrional do maciço de Itaíba (Santos, 1971). Brito Neves (1975) distinguiu nessa região a fa.ixa de dobramentos Pajeú-Paraíba, incluindo-a em uma ampla região geossinclinal em mosaico, situada entre as plataformas de São Luís/Gurupi e São Francisco, cuja tectogênese desencadeou-se no final do Pré-cambriano.

O maciço de Itaíba, de natureza diatexítica-granitóide, foi descrito e reconhecido como de afinidade cratogênica inicialmente por Santos (1971), embora sem confirmação geocronológica. Recentemente, porém, Brito Neves (1975) encontrou uma isócrona de

*CPRM, Superintendência Regional de Recife

** SUDENE, Departamento de Recursos Naturais, Recife

O maciço de Itaíba foi redenominado por esse autor de maciço Pernambuco-Alagoas 


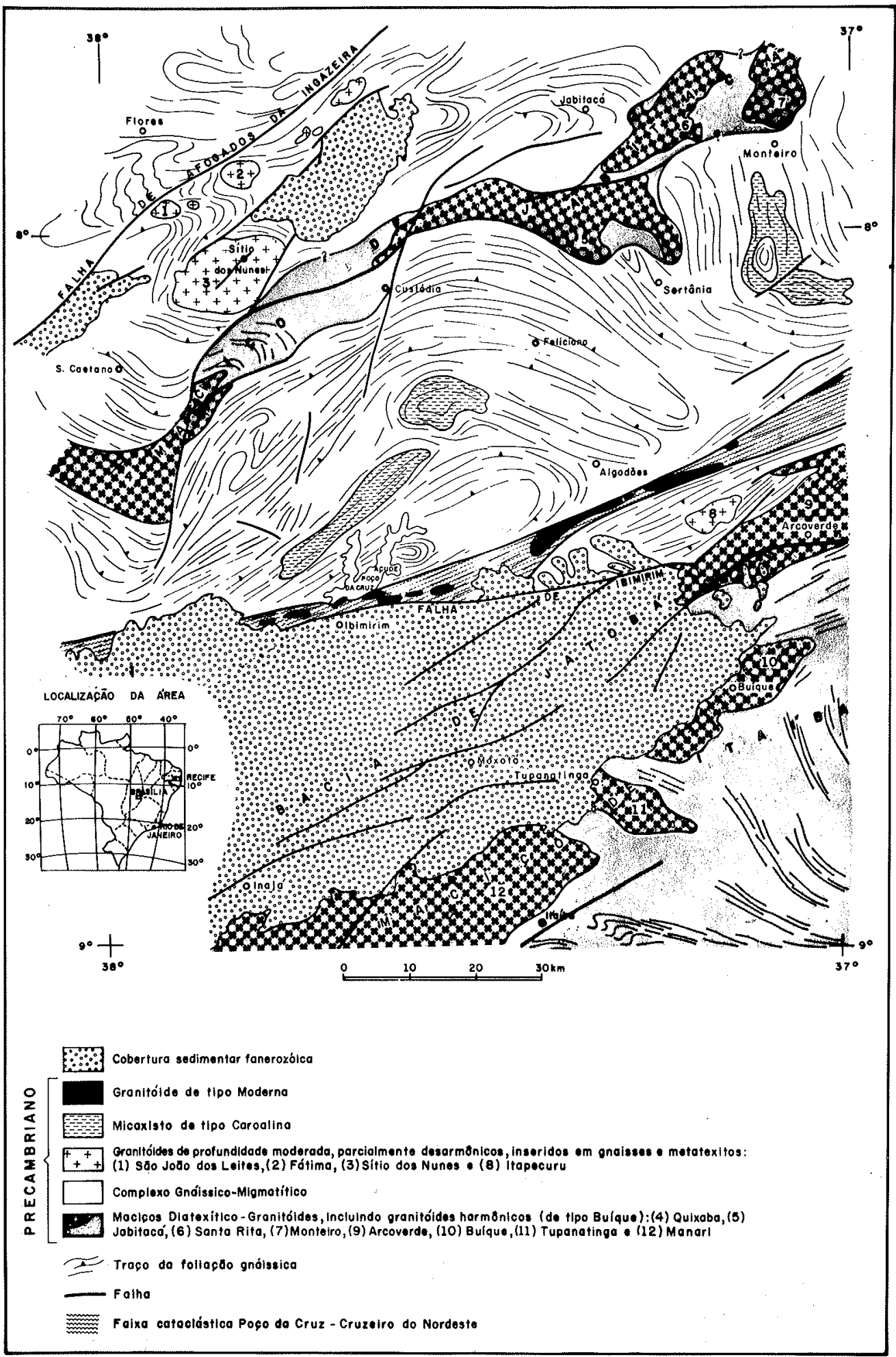

Figúra 1 - Distribuição dos granitóides de parte da região central de Pernambuco 
$1780 \pm 300$ m.a. em cordierita leptinitos e gnaisses graníticos desse maciço, enquanto que os granitos alinharam-se segundo uma isócrona de $650 \pm 30$ m.a. Entretanto uma datação de $2300 \pm 105$ m.a. foi considerada por esse autor como produto de homogeneização isotópica incompleta de rochas antigas, durante o ciclo Transamazônico, de modo que o maciço teria se formado no ciclo Guriense/Jequié (2 $800 \pm 200$ m.a.).

A faixa de dobramentos é de dificil reconstituição estratigráfica; distingue-se um amplo complexo gnáissico-migmatítico e granitóide, os micaxistos de tipo Caroalina e os granitóides tectoníticos de tipo Moderna (Fig. 1).

O complexo gnáissico-metatexítico foi diferenciado pela natureza do seu paleossoma em três seqüências: pelito-psamítica (tipo São Caetano), pelítica (tipo Sertânia) e metabasítica (tipo Feliciano). A migmatização atuou indistintamente nessas seqüências, resultando migmatitos de estruturas predominantemente estromáticas, flebíticas e dobradas; estruturas oftálmicas aparecem apenas associadas às faixas de compressão e cisalhamento, enquanto que estruturas agmáticas ou do tipo raft são comuns nas rochas da seqüência metabasítica. Tipos mais difusos (schlieren ou nebulíticos) são freqüentes no maciço diatexítico-granitóide de Jabitacá, que constitui uma réplica, em menor escala, do maciço de Itaíba, inclusa na faixa de dobramentos.

Os micaxistos de tipo Caroalina ocorrem em sinclinais isolados dentro do substrato gnáissico-migmatítico; são constituídos por sillimanita-(cianita)-almandina-biotita xistos, os quais contêm numerosas lentes calcárias e um horizonte quartzítico basal descontínuo (quartzito Jaramataia). Por essas características e pela parcial desarmonia com o processo migmatítico do complexo inferior, foram considerados como uma unidade independente, equiparável aos ectinitos contidos nas faixas metamórficas brasilianas melhor preservadas do Nordeste (tipos Cachoeirinha-Salgueiro e Seridó). As "calhas" nas quais estão contidos os micaxistos Caroalina representam, portanto, raízes de uma faixa metamórfica maior, hoje já bastante erodida.

Os granitóides dessa região acham-se inseridos como pequenos corpos dentro do complexo gnáissico-migma títico e como corpos maiores associados aos maciços de Jabitacá e I taíba. Entre os do primeiro tipo, filiam-se os granitos dos arredores do Sítio dos Nunes, aqui estudados (veja a Fig. 1), os quais acham-se encaixados por rochas da seqüência São Caetano. Esses dois tipos de granitóides apresentam características diversas: enquanto que os primeiros são parcialmente desarmônicos e, como tal, de contatos relativamente nítidos e texturalmente homogêneos, os últimos são absolutamente concordantes e de contatos difusos com as encaixantes, representando verdadeiros granitóides de anatexia (Raguin, 1957); estes últimos foram por nós denominados de granitóides de tipo Buíque (Santos, 1971).

GARACTERES PETROGRÁFICOS DO MACIÇO PRINCIPAL O granito do Sítio dos Nunes mostra-se, em afloramento, como uma rocha de coloração rósea, granulação média a grossa, não-orientada ou apenas levemente orientada. Ao microscópio, demonstra ser constituído quase que exclusivamente por microclina, plagioclásio e quartzo, sendo que a biotita nunca atinge $10 \%$ do total da rocha. A textura é granular, pouco ou nada orientada, por vezes cataclástica. A microclina é o mineral mais abundante nos tipos mais comuns, variando entre 40 e $50 \%$ do volume total. Em geral, mostra-se como cristais xenomórficos, intersticiais, às vezes bem-desenvolvidos, pertíticos, com extinção ondulante freqüente; são comuns inclusões de plagioclásio e de mirmequita. $\mathrm{O}$ plagioclásio varia de 22 a $37 \%$ do volume da rocha, só raramente atingindo mais de $40 \%$, justamente nos tipos menos ácidos. Em geral é oligoclásio ou, menos freqüentemente, andesina. Aparece em 
cristais xenomórficos, às vezes mais ou menos hipidiomórficos, geminados segundo a lei da albita ou albita-Carlsbad.

$\mathrm{O}$ quartzo, normalmente xenomórfico, ocorre em pequenos cristais fraturados, com extinção ondulante, ou aparece em aglomerados que se distribuem entre os grandes cristais da rocha. A biotita aparece em pequenas lamelas, parcialmente alteradas para penina e muscovita. Como acessórios, ocorrem apatita e opacos.

A composição modal de várias amostras do granito do Sítio dos Nunes é apresentada na Tab. I. E interessante observar que variedades granodioríticas ou com tendência para tal (amostras 7 e 8), mais pobres em microclina e com elevado teor em plagioclásio, aparecem nas proximidades dos enclaves de calcário; a amostra 7, por exemplo, foi retirada a apenas $8 \mathrm{~m}$ do conţa to granito-calcário. Esse fato denuncia um processo de endomorfismo, que é confirmado pela presença de fácies modificadas do granito, na proximidade dos calcários nele incluídos, como se verá mais adiante.

Tabela I - Composição modal de várias amostras do granito de Sítio dos Nunes*

\begin{tabular}{lrrrrrrrr}
\hline & 1 & 2 & 3 & 4 & 5 & 6 & 7 & 8 \\
\hline \hline Microclina & 40,54 & 43,60 & 41,44 & 51,23 & 40,94 & 42,38 & 36,47 & 30,78 \\
\hline Plagioclásio & 36,33 & 22,78 & 27,54 & 22,05 & 37,00 & 36,57 & 40,29 & 49,31 \\
\hline Quartzo & 13,01 & 29,69 & 24,37 & 18,42 & 14,08 & 17,02 & 17,65 & 15,10 \\
\hline Biotita & 9,67 & 2,55 & 5,36 & 6,82 & 7,08 & 2,88 & 2,84 & 3,23 \\
\hline Acessórios & 0,43 & 1,36 & 1,27 & 1,45 & 0,87 & 1,12 & 2,73 & 1,56 \\
\hline Total & 99,98 & 99,98 & 99,98 & 99,97 & 99,97 & 99,97 & 99,98 & 99,98 \\
\hline
\end{tabular}

1. Granito monzonítico hololeucocrático, estrada Sítio dos Nunes, Serra Talhada.

2. Granito subalcalino hololeucocrático, estrada Sítio dos Nunes, Serra Talhada.

3. Granito monzonítico hololeucocrático, Tamboril, na estrada Sítio dos Nunes, Serra Talhada.

4. Granito subalcalino hololeucocrático, na estrada Sítio dos Nunes, Flores.

5. Granito monzonítico hololeucocrático, sopé da Serra do Boqueirão.

6. Granito monzonítico hololeucocrático, estrada Sítio dos Nunes, Malhada do Boqueirão.

7. Granito monzonítico hololeucocrático, Tamboril.

8. Granodiorito hololeucocrático, entre Tamboril e Boqueirão.

*Classificação segundo Jung e Brousse (1959)

ENCLAVES DO GRANITO DE SÍTIO DOS NUNES No seio do granito, observa-se a presença de numerosos enclaves enalógenos, de natureza e dimensões variadas. Esses enclaves, que atingem dimensões desde menos de um metro até poucos quilômetros de extensão, são de xistos, gnaisses, calcários e anfibolitos; apenas os enclaves de calcário puderam ser convenientemente mapeados, sendo indicados, porém, no mapa geológico anexo, as áreas de maior freqüência dos demais tipos. Os enclaves de xistos e gnaisses apresentam contatos difusos com o granito, enquanto que os de gnaisses calcossilicáticos e anfibolíticos, anfibolitos e calcários mostram contatos nítidos, sem acentuada evidência de feldspatização e granitização (Fig. 8). O grau de resistência à granitização desses enclaves é comparável, aliás, ao descrito por Pitcher (1953) para as rochas incluídas no granodiorito de Thorr, Go. Donegal, Irlanda. 
Dentre os enclaves gnáissicos, os tipos litológicos mais freqüentes são biotita gnaisses, biotita-muscovita gnaisses, hornblenda gnaisses, hornblenda-epídoto-diopsídio gnaisses; biotita xistos foram observados a oeste de Tamboril e próximo à Cacimbinha, enquanto que um biotita-muscovita migmatito oftálmico foi observado pouco a oeste do Sítio dos Nunes $^{2}$.

Os calcários distribuem-se numa faixa concêntrica quase contínua em torno do núcleo do maciço (Fig. 2). Em geral, são puros, ou possuem uma pequena percentagem de grafita ou flogopita; entretanto, associam-se a eles skarns e fácies modificadas do granito. Por exemplo, junto aos calcários da região de Piabas, ocorre um hornblenda-granada monzonito com calcita, epídoto, titanita e resquícios de diopsídio. Próximo ao enclave calcário de Tamboril, foi encontrado um diopsídio-monzonito com hornblenda, epídoto, calcita, titanita, apatita e zircão. Esse fenômeno de hibridização entre o granito em formação e os calcários incluídos (endomorfismo e exomorfismo) é referido por Didier (1973), e um dos exemplos semelhantes é o do maciço de Lys-Caillaouas, nos Pirineus, onde fácies dioríticas do granito são encontradas no prolongamento de enclaves calcários; no granito de Costabonne, nessa mesma cadeia, Guitard e Laffitte (1958) citam-se fácies modificadas do granito produzidas por endomorfismo, na zona de contato com os skarns; essas fácies caracterizam-se pela ausência de microclina, pobreza de micas primárias, presença eventual de minerais cálcicos, embora uma abundância de quartzo tenha sido observada, diferentemente do nosso caso.

Típicos skarns aparecem na base da lente de Tamboril, os quais se acham constituídos por diopsídio, epidoto, carbonato, escapolita e opaco. O diopsídio ocorre abundantemente em grandes cristais irregulares, argilizados e uralitizados, corroídos por feldspatos e quartzo e alterados para epídoto; este último é também bastante comum, enquanto que a escapolita aparece em cristais bem desenvolvidos, associados ao diopsídio, ou acompanhando formas de transformação do feldspato. Em outras variedades, o processo de epidotização é menos intenso, ocorrendo diopsídio e escapolita em percentagens elevadas, secundados por carbonato, quartzo e epídoto, sem feldspatos.

Dos tipos petrográficos aqui descritos, apenas os gnaisses com duas micas são característicos da seqüência São Caetano encaixante, porquanto xistos e gnaisses biotíticos, assim como calcários e anfibolitos, são mais comuns na seqüência Sertânia.

Em resumo, observa-se que os enclaves são exclusivamente de rochas metamórficas e que os membros da seqüência aluminosa não sofreram os efeitos de metamorfismo térmico; ao contrário, o contato difuso é indicativo de um processo de granitização direta dos mesmos (Didier e Roques, 1960). Já as rochas de filiação anfibolítica e carbonática não mostram indícios de granitização, desenvolvendo-se junto aos calcários, produtos de endo e exomorfismo dos granitos, indicativos da elevação da temperatura e da existência de um mecanismo de troca metassomática entre o granito e os enclaves englobados.

MODO DE JAZIMENTO, CONTATOS E ESTRUTURAS DO MACIÇO PRINGIPAL O maciço de Sítio dos Nunes possui uma forma grosseiramente elipsoidal, com seu eixo maior alongado na direção nordeste-sudoeste; o centro do maciço corresponde ao seu traço morfológico mais característico - a serra do Boqueirão. $O$ contato com as encaixantes é concordante e não se observa a presença de produtos de metamorfismo termal. Nos limites norte e sul, as encaixantes dispõem-se com foliação vertical ou com forte ângulo de mergulho,

? Os biotita gnaisses na base da lente calcária do Serrote de Campo Alegre são cortados por dois veios de basalto extremamente alterados; os afloramentos, entretanto, não permitiram definir se se trata de um magmatismo básico pré ou pós-granítico 


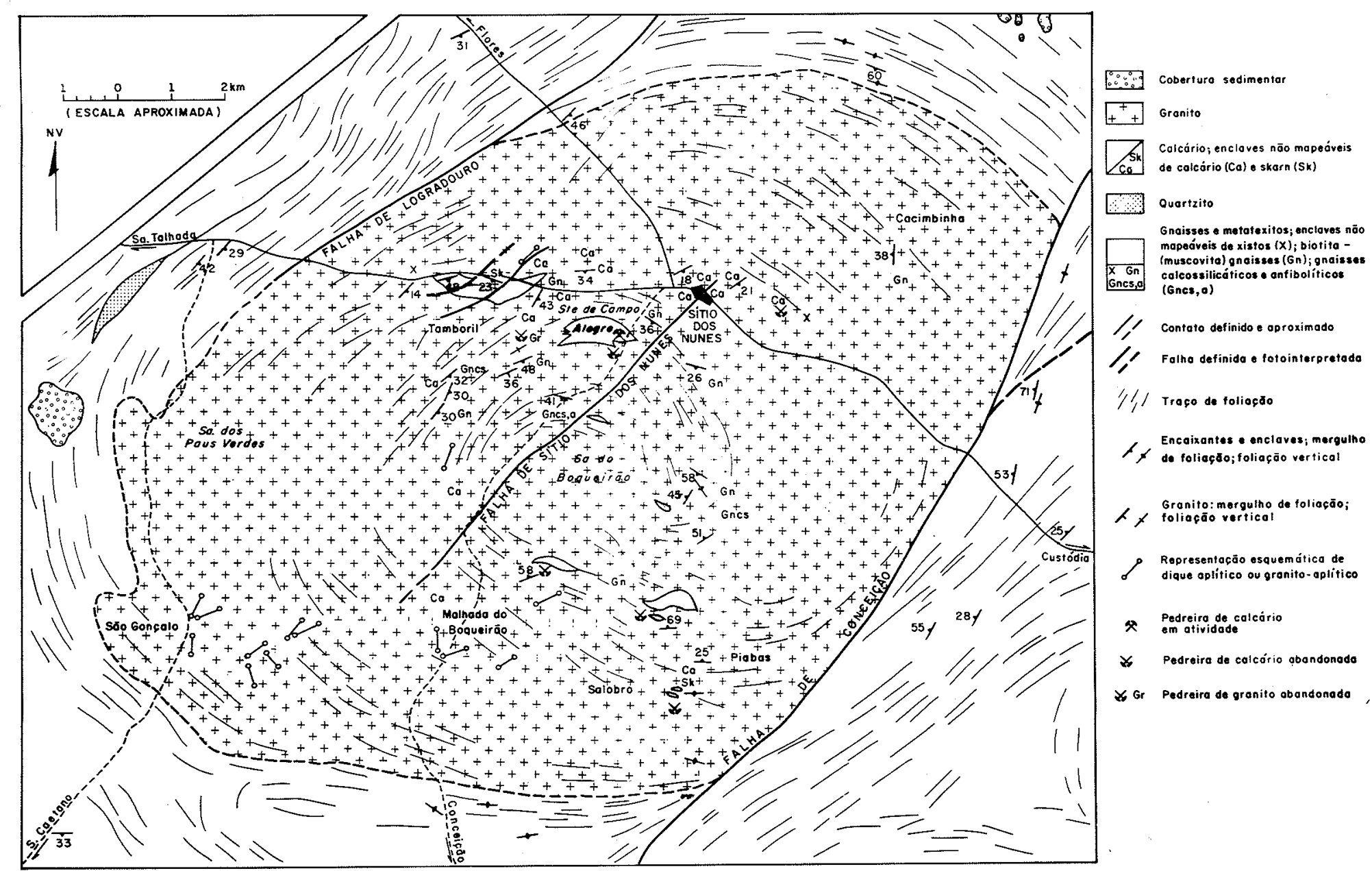

Figura 2 - Mapa geológico do maciço granítico de Sítio dos Nunes, PE 
mas, a oeste e a noroeste, aparecem mergulhos suaves $\left(30\right.$ a $\left.40^{\circ}\right)$, dirigidos para o interior do maciço.

Internamente, observa-se o desenvolvimento local de estruturas orientadas, marcadas principalmente pela biotita, acompanhando a disposição espacial das encaixantes. Na pedreira de Tamboril (Fig. 2), aparece uma vaga foliação no granito, decorrente da presença de schlieren hiperbiotíticos orientados segundo planos verticais (Fig. 3); de acordo com Dennis (1972), essas estruturas representam planos de fluxo do material granítico em ascensão.

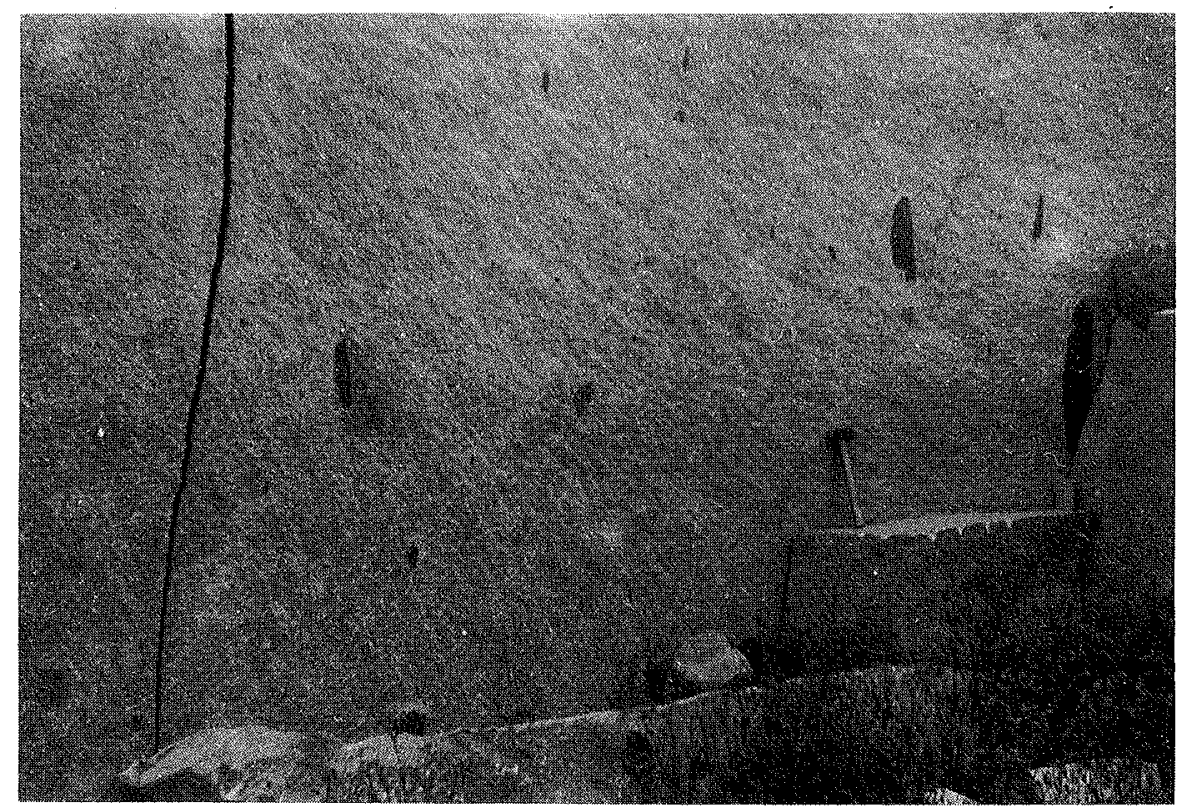

Figura 3 - Schlieren hiperbiotíticos do granito de Sítio dos Nunes, aflorando na pedreira de Tamboril; observe-se a forma ovalada e o alongamento vertical dessas concentrações

Os contatos a oeste e a noroeste são feitos pelas falhas de Conceição e Logradouro, que se dispõem em direção aproximadamente paralela à grande falha de Afogados da Ingazeira. Falhas paralelas às duas do contato estão presentes no interior do maciço, devendo fazer parte do mesmo sistema; dessas a mais importante é a que passa no próprio distrito de Sítio dos Nunes, sendo bem caracterizada pelo desenvolvimento de brechas no granito, no sopé da serra do Boqueirão, e num enclave calcário existente no povoado (Fig. 4); uma pequena falha, que passa em Tamboril, é marcada não somente pela "brechação" do calcário, como também pela penetração de um dique granítico com tendência aplítica (Fig. 7). Falhas de pequeno rejeito são observadas também nessa mesma lente, próximas do contato com o granito, como se observa em um corte na estrada Sítio dos Nunes-Serra Talhada (Fig. 8A).

Pelas estruturas descritas, deduz-se que o maciço de Sítio dos Nunes representa um pequeno batólito de forma grosseiramente cilíndrica, com tendência a alargamento em direção à superfície.

OS MACIÇOS MENORES E AS ROGHAS FILONIANAS Associados ao granito de Sítio dos Nunes, ocorrem dois pequenos maciços: os stocks de Fátima e de São João dos 


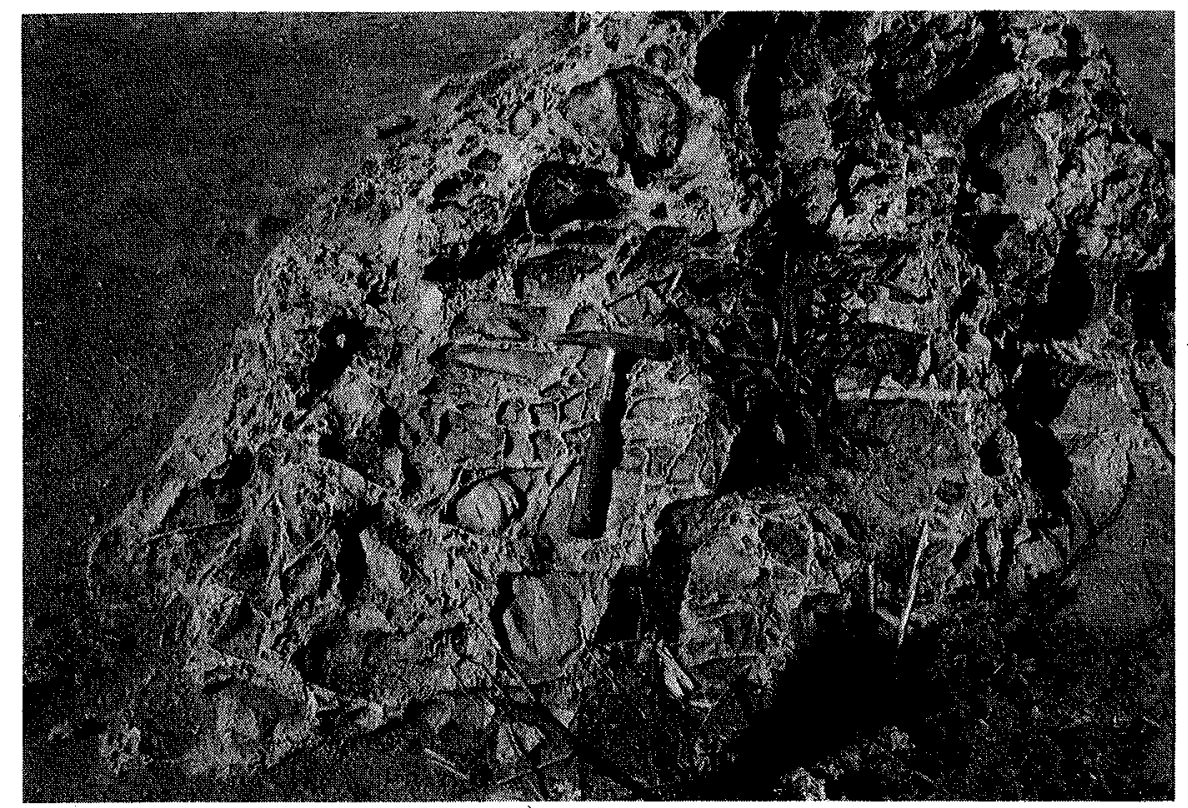

Figura 4 - Calcário brechado da falha de Sítio dos Nunes. Afloramento no povoado de mesmo nome
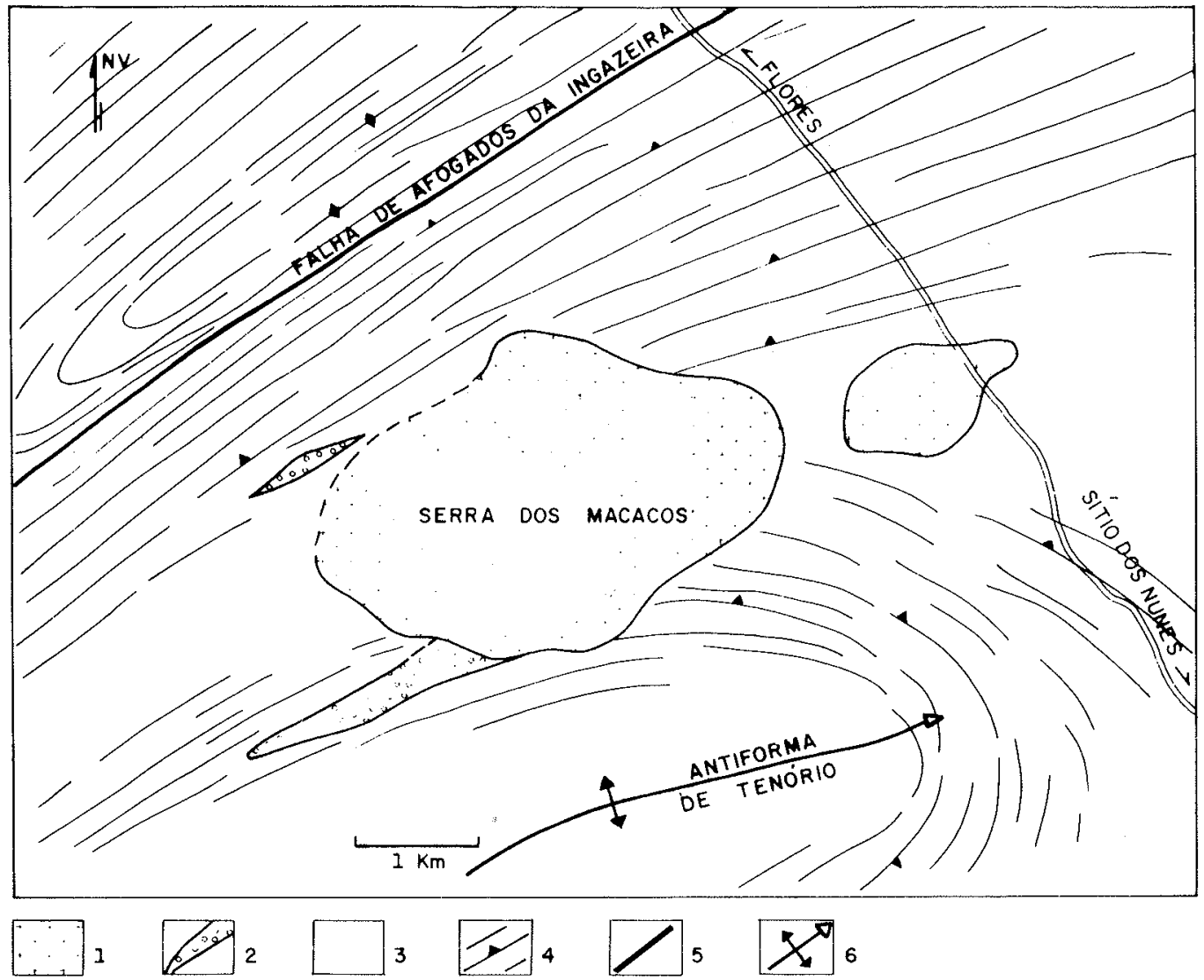

Figura 5 - Esboço Geológico do Maciço de São João dos Leites. 1) granito, 2) quartzito, 3) gnaisses e migmatitos, 4) foliação com indicação do mergulho, 5) falha, 6) antiforma com eixo mergulhante 
Leites, situados respectivamente a oeste e norte desses povoados. Ambos são muito bem evidenciados morfologicamente, através das serras do Zuza e dos Macacos.

O granito de São João dos Leites é um maciço nitidamente discordante, como mostra o esboço geológico anexo (Fig. 5). Na parte sudoeste do corpo, observa-se a supressão de uma lente quartzítica; não foram vistos enclaves de quartzito, mas uma amostra de granito, coletada próxima do contato, evidenciou um elevado teor em quartzo (amostra 3, Tab. II).

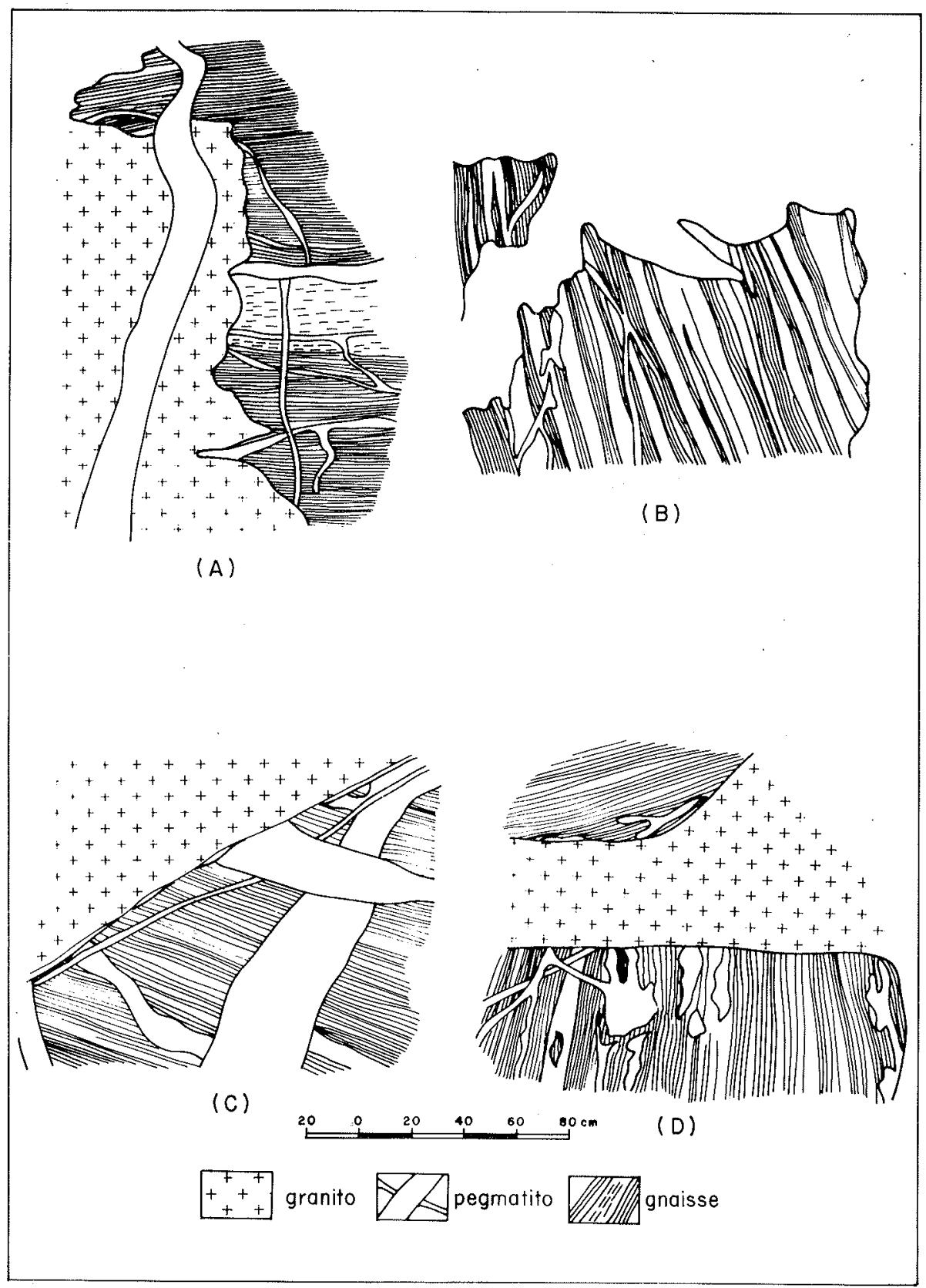

Figura 6 - Detalhe de enclaves migmatíticos no granito de Fátima 
E interessante assinalar ainda a presença de um sillimanita-biotita homfels no contato do maciço satélite existente a este-nordeste do corpo principal.

Esse granito mostrou ser o mais alcalino de todo o cortejo, como pode-se observar das composições modais exibidas na Tab. II. Ao microscópio, ele apresenta os mesmos fenômenos do granito de Sítio dos Nunes: microclina dominante, em cristais irregulares; plagioclásio do tipo oligoclásio $\left(\mathrm{An}_{28}\right) \mathrm{cm}$ cristais mais ou menos hipidiomórficos; quartzo, biotita e clorita, além dos acessórios apatita, allanita e zircão.

O stock de Fátima é um maciço igualmente discordante, mas seus contatos diretos com as encaixantes não foram vistos. Em um afloramento no norte do maciço, foram observados numerosos enclaves de migmatitos com estrutura flebítica, possuindo um paleossoma de biotita gnaisses e um neossoma granítico e pegmatítico (Fig. 6). A discordância existente entre as direções de foliação desses enclaves é uma evidência da mobilidade do meio (Fig. 6D). Importante, também, é o fato de que a presença de enclaves migmatíticos denuncia a existência de processos metatexíticos anteriores à formação do granito. A composição modal de uma amostra colhida neste local revelou uma natureza semelhante àquela do maciço principal (amostra 4, Tab. II).

Os tipos filonianos são comuns no interior do stock de São João dos Leites como verdadeiros aplitos, e no maciço de Sítio dos Nunes como aplitos ou granitos de granulação fina, com tendência aplítica (Fig. 7).

Neste último, poucas vezes foram vistos esses filões cortando enclaves, devendo-se registrar, entretanto, um granito aplítico muito alterado cortando os calcários em Tamboril (Fig. 8A) e outro filão de natureza duvidosa no serrote de Campo Alegre (Fig. 8C); a lente calcária de Tamboril é atravessada também por um dique pegmatítico, com $0,5 \mathrm{~m}$ de espessura, no qual se desenvolveu chilled margin. Uma estrutura curiosa foi observada em

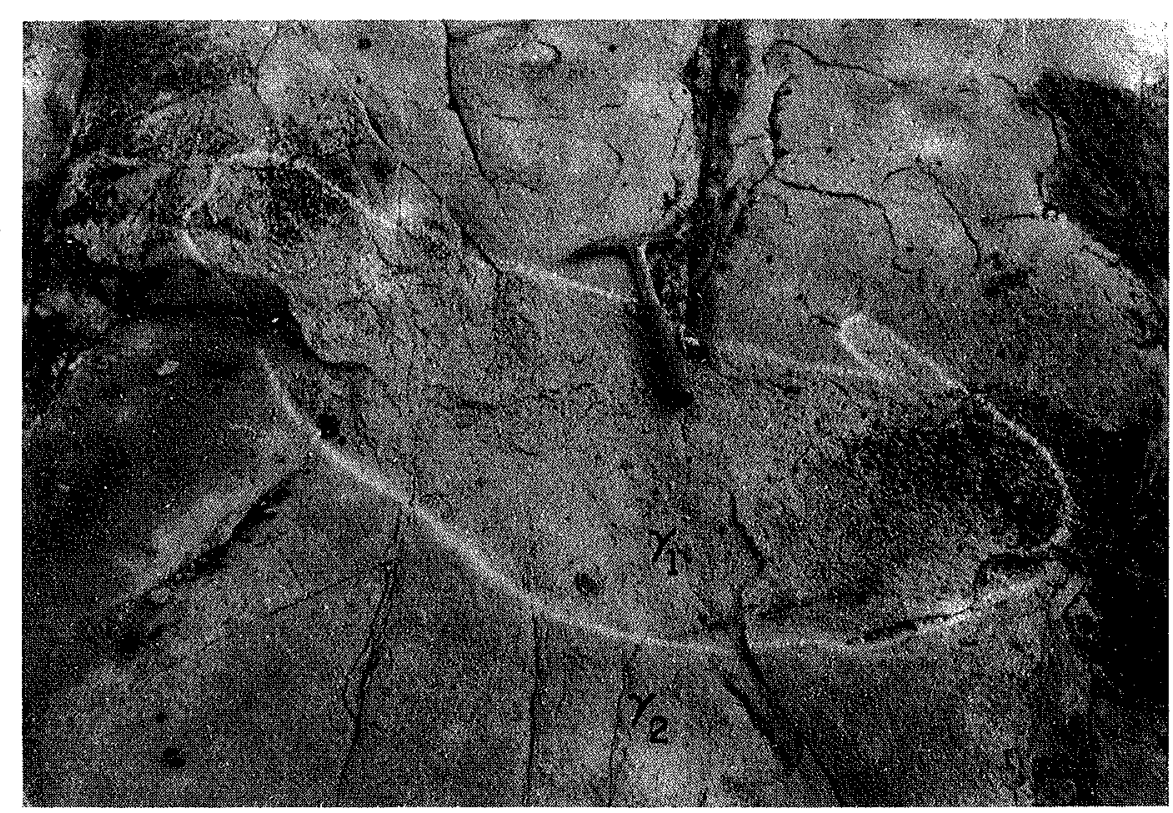

Figura 7 - Granito aplítico filoniano $\left(\gamma_{2}\right)$, introduzido ao longo da falha de Tamboril, incluindo um enclave do granito de Sítio dos Nunes $\left(\gamma_{1}\right)$. Afloramento na margem do Riacho do Meio, 'I'amboril 


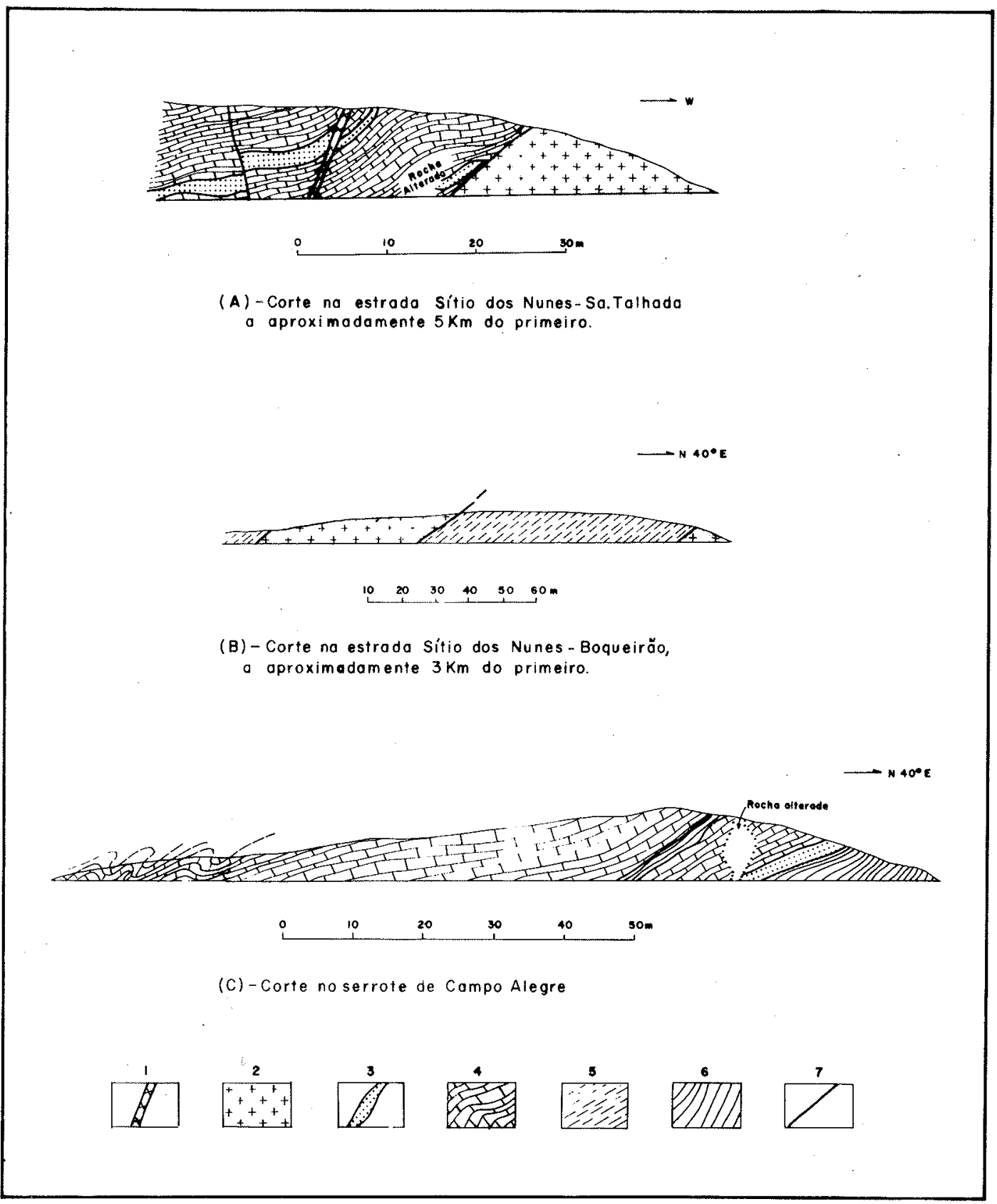

Figura 8 - Detalhes de contatos e estruturas dos enclaves do granito de Sítio dos Nunes. 1) granito aplítico, 2) granito, 3) rocha calcossilicática, 4) calcário, 5) anfibólio-epídoto gnaisse, 6) biotita gnaisse, 7) falha 
um afloramento desses filões, cortando o granito entre Conceição e São Gonçalo. Ali, aparece um filão aplítico, atravessado e deslocado por outro de geração mais nova (Fig. 9). O filão antigo é, em certo trecho, interrompido pelo próprio granito que está penetrando; tudo se comporta como se o filão cortasse o granito e em certos locais fosse assimilado por ele. Tais tipos de filões foram chamados por Raguin (1957) de filóes congêneres dos granitos, i.e., formados quando estes ainda não estavam totalmente solidificados.

Foram estudadas várias amostras desses filões, tendo-se constatado uma composição similar à dos maciços, havendo apenas uma mudança na granulação e uma diminuição do teor de biotita (amostras 5 e 6, Tab. II).

MECANISMO DE FORMAÇÃO DOS GRANITOS E SUA POSIÇÃO DENTRO DA TECTOGENNESE BRASILIANA Segundo Walton (1955), dois fatores são importantes para a análise da natureza dos granitos: (1) o grau de desarmonia de nível energético entre o granito e sua encaixante; (2) o room problem. O gradiente de desarmonia energética dos nossos granitos em relação às encaixantes é pequeno e reflete-se nas restritas ocorrências de hornfels e de skarns. Entretanto, as relações estruturais indicam que os granitos deslocaram as rochas metamórficas que anteriormente existiam no espaço agora por eles ocupado.

Os maciços menores são discordantes com as encaixantes e o modelo indica que ocorreu um deslocamento brusco das rochas originalmente aí existentes. Eles teriam penetrado por um processo de forceful injection. Já a concordância do granito de Sítio dos Nunes com as encaixantes, sugere um mecanismo diverso; aparentemente, a desarmonia energética é menor que a dos outros maciços, porquanto não se observa a formação de hornfels, nem nas encaixantes, nem nos enclaves; apenas nos calcários ocorre uma ligeira transformação para skarns. Se considerarmos, porém, a evolução da série migmatítica normal, constata-se que o granito de Sítio dos Nunes é zoneograficamente anômalo, pois situa-se em área com

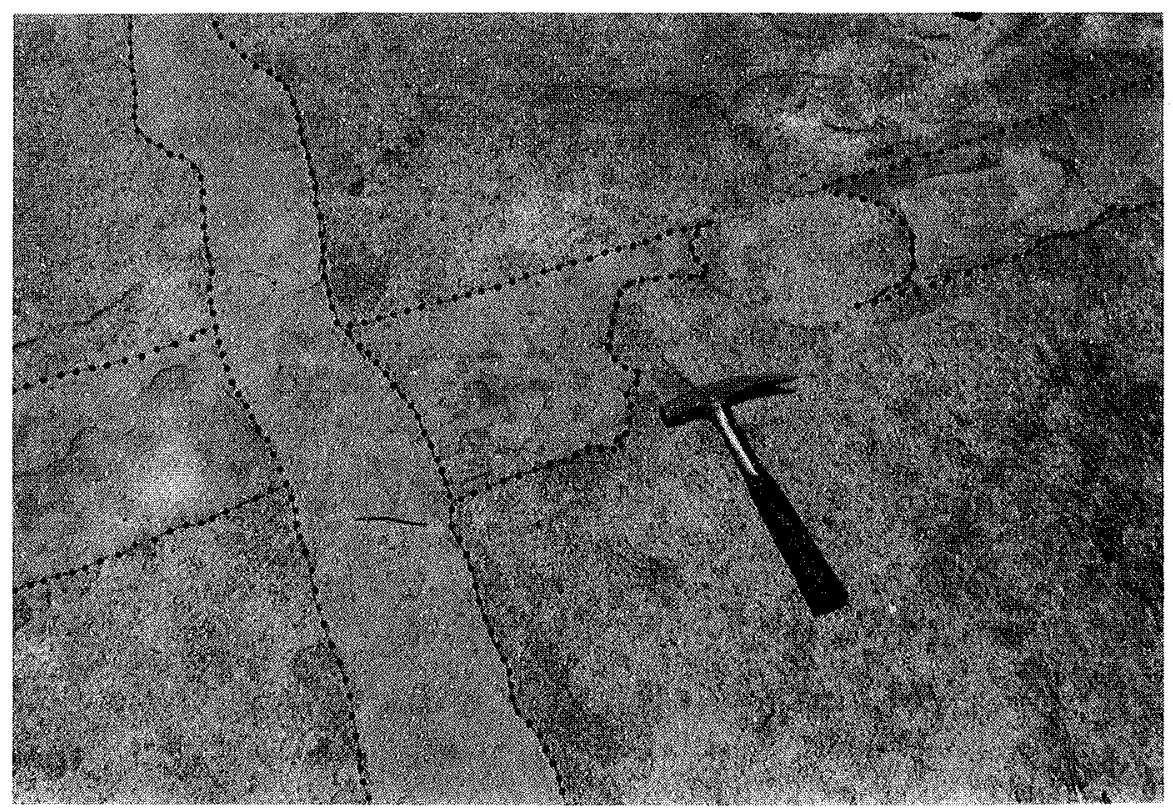

Figura 9 - Filão aplítico congênere do granito de Sítio dos Nunes, mostrando zona de descontinuidade longitudinal. Afloramento entre São Gonçalo e Malhada do Boqueirão 
Tabela II - Composição modal dos maciços menores e das rochas filonianas*

\begin{tabular}{lcccccc}
\hline & 1 & 2 & 3 & 4 & 5 & 6 \\
\hline \hline Microclina & 41,33 & 48,60 & 21,2 & 39,30 & 20,16 & 43,36 \\
\hline Plagioclásio & 24,92 & 21,59 & 19,4 & 37,40 & 50,98 & 18,80 \\
\hline Quartzo & 27,43 & 26,75 & 49,0 & 18,75 & 19,18 & 28,29 \\
\hline Biotita & 6,30 & 3,04 & 10,4 & 4,20 & 7,21 & 8,27 \\
\hline Acessórios & tr & $\operatorname{tr}$ & $\operatorname{tr}$ & 0,35 & 2,46 & 1,25 \\
\hline Total & 99,98 & 99,98 & 100,00 & 100,00 & 99,99 & 99,97 \\
\hline
\end{tabular}

1. Granito subalcalino hololeucocrático, Serra dos Macacos.

2. Granito subalcalino hololeucocrático, Serra dos Macacos.

3. Granito monzonítico hololeucocrático, Serra dos Macacos.

4. Granito monzonítico hololeucocrático, Serra do Zuza, próximo à Fátima.

5. Granodiorito hololeucocrático, entre Boqueirão e Tamboril.

6. Granito subalcalino hololeucocrático, próximo à Conceição.

*Classificação segundo Jung e Brousse (1959)

dominância de rochas sem acentuado nível de mobilidade. Isso denuncia um certo grau de aloctonia, o que, aliás, é confirmado pela existência de planos de fluxo na pedreira de Tamboril. Por outro lado, a presença de numerosos enclaves, principalmente na sua parte interna, sugere um mecanismo de stoping. A quase harmonia estrutural desses enclaves com as encaixantes sugere, porém, um processo lento de intrusão, para o qual a própria assimilação do material englobado teria contribuído para a formação de um meio mais viscoso.

Indubitavelmente, essas rochas fazem parte de um mesmo ciclo de atividade granítica, representando diferentes estádios de mobilidade do processo de granitização. Como pensa Elsasser, 1963 (in Brown e Fyfe, 1970), somente grande volume de líquido, com suficiente rapidez de ascenção, seria capaz de evitar o resfriamento e a conseqüente cristalização, uma vez que parte da massa, ao ser cristalizada, diminui sensivelmente o contraste de densidade necessário para a injeção. É possível, então, que esse princípio tenha sido o responsável pela diferença de comportamento aqui constatada.

Em oposição a esse arcabouço tipicamente intrusivo, os granitóides de tipo Buíque apresentam um quadro bastante diverso, estando intimamente associados ao modelo migmatítico no qual estão inseridos. Eles possuem uma composição predominantemente granodiorítica, tendo evoluído através de processos de blastese feldspática, metatexia e diatexia, como foi descrito em Santos (1971). Recente investigação efetuada por Brown et al. (1972), em porfiroblastos de magnetita titanífera dos migmatitos de Algodões, Sertânia, confirmam a existência de processos de anatexia parcial numa faixa de temperatura entre 750 e $800^{\circ} \mathrm{C}$ nessa área. Aliás, a origem ana téctica de migmatitos e granitos em faixas orogênicas tem sido defendida e comprovada experimentalmente por numerosos autores (e.g., Brown e Fyfe, 1970; Hall, 1971; Winkler, 1974).

O posicionamento desses dois tipos de granito dentro da mesma faixa de dobramentos, a similaridade de caracteres petrográficos, um enriquecimento alcalino nos termos superiores e algumas datações geocronológicas confirmam a existência de um único ciclo 
de atividade granítica. Acredita-se, então, que os granitos dos arredores de Sítio dos Nunes representem os termos mais evoluídos, alóctones, de uma série granítica (na acepção de Read, 1955), na qual os granitóides de tipo Buíque seriam os membros profundos, de formação in situ. De certa forma, esse esquema parece similar ao modelo imaginado por Glangeaud (1959) para o plutonismo siálico dos Pirineus orientais, ou aos estádios de mobilização crustal, descritos por Mehnert (1968): (1) recristalização e blastese feldspática; (2) metatéxis, com formação de fundidos quartzo-feldspáticos separados de um restito; (3) diatéxis, dando origem a magmas palingenéticos, sem formação de restitos; (4) mobilização e intrusão desses neomagmas.

É porém improvável, como supõem Brown e Fyfe (1970), que eles tenham sido formados sincronicamente; da comparação com os tipos magmatectônicos de Eskola (1932), detalhadamente caracterizados por Marmo (1967), conclui-se que os granitóides de tipo Buíque são sincinemáticos, enquanto que os de tipo Sítio dos Nunes, provavelmente, tardicinemáticos.

Almeida et al. (1967) descreveram, na região de dobramentos caririanos, diversos tipos de rochas graníticas sin, tardi e pós-orogênicas. As características dos granitos tàrdiorogênicos de tipo Itapetim coincidem, em grande parte, com a dos maciços aqui descritos, embora esses autores tenham atribuído a essas rochas uma natureza principalmente filoniana. Brito Neves (1975) atribui à granitização sincinemática uma idade de $650 \pm 30$ m.a., como mencionado anteriormente, formando-se os granitóides preferencialmente no embasamento da faixa (maciços medianos e geanticlinais). Os granitos tardicinemáticos teriam se formado há $540 \pm 30$ m.a., instalando-se no complexo gnáissico-migmatítico, de acordo com determinações desse mesmo autor. Por essa concepção, toda a atividade granítica teria, portanto, origem regenera tiva, i.e., resultaria do rejuvenescimento de maciços antigos durante o ciclo brasiliano, num mecanismo similar ao concebido por Raguin (1966) para os granitos de cráton, descritos por Arnould (1961) na Costa do Marfim e no Alto Volta meridional.

Agradecimentos, Os autores desejam agradecer ao professor Reinhardt Adolfo Fuck, pela leitura do manuscrito e pelas críticas e sugestões apresentadas.

\section{BIBLIOGRAFIA}

ALMEIDA, F. F. M. de, LEONARDOS, JR., O.H. e VALENĢA, J. - 1967 - Granitic rocks of North-Eeast South America - UNESCO, SC/CS/143/2, 51 pp. (inédito)

ALMEIDA, F.F. M. de, MELGHER, G.C., CORDANI, U., KAWASHITA, K. e VANDOROS, P. - 1968 - Radiometric age determinations from Northern Brazil. Bol. Soc. Bras. Geol., 17(1): $3-15$

ARNOULD, M. - 1961 - Étude géologique des migmatites et des granites précambriens du nord-est de la Cote d'Ivoire et de la Haute-Volta méridionale. Bur. Rech. Géol. Min., mém. n. ${ }^{\circ}$, $174 \mathrm{pp}$.

BRITO NEVES, B. B. de - 1975 - Regionalização geotectônica do Precambriano nordestino. Inst. Geociências da Universidade de São Paulo, tese de doutoramento, $198 \mathrm{pp}$. (inédito)

BROWN, G. C. e FYFE, W. S. - 1970 - The production of granitic melts during ultrametamorphism. Contr. Miner. Petrol., 28: 310-318

BROWN, G. C., FYFE, W.S. e LEONARDOS, Jr., O. H. - 1972 - Migmatization temperature of a rock from Algodões, Pernambuco, Brazil. An. Acad. bras. Ciênc., 44 (1): 69-76

DENNIS, J. G. - 1972 - Structural Geology. Ronald Press Co., 532 pp.

DIDIER, J. - 1973 - Granites and their enclaves. Amsterdam, Elsevier Sci. Publ. Co., 393 pp. 
DIDIER, J. e ROQUES, M. - $19 \hat{9} 60$ - Nature des enclaves dans les différents types de granites du Massif Gentral Français. In The granite - gneiss problem. Intern. Geol. Congr., Norden, Sect. 14, pp. 194-206.

ESKOLA, P. - 1932 - On the origin of granitic magmas. Tscherm. Min. Petr. Mitt., 42 (5-6): 456-481

GLANGEAUD, L. - 1959 - Le plutonisme sialique ses relations avec le métamorphisme dans les Pyrénées orientales et centrales. Bull. Soc. Géol. France, 8 (8): 961-978

GUITARD, G. e LAFFITTE, P. - 1958 - Les calcaires métamorphiques et les skarns du Pic de Costabonne (Pyrénées-orientales). Sci. Terre, Nancy, 6 (1-2): 57-137

HALL, A. - 1971 - The relationship between geothermal gradient and the composition of granitic magmas in orogenic belts. Contr. Miner. Petrol., 32: 186-192

JUNG, J. e BROUSSE, R. - 1959 - Classification modale des roches éruptives. Masson et Cia Editeurs, Paris

MARMO, V. - 1967 - On granites, a revised study. Bull. Gomm. Géol. Finlande., 227, 83 pp.

MEHNERT, K. R. - 1968 - Migmatites and the origin of granitic rocks. Amsterdam, Elsevier Sci. Publ. Co., 393 pp.

PITCHER, W. S. - 1953 - The migmatitic older granodiorite of Thorr District, Co. Donegal. Quart. J. Geol. Soc. London., 108: 413-446

RAGUIN, E. - 1957 - Géologie du granite. Paris, Masson et Cie., 257 pp.

RAGUIN, E. - 1966 - Sur la classification des granites et l'importance des granites de cratons. C. R. Acad. Sci. Paris, 262 (3): 333-336

READ, H. H. - 1955 - Granite series in mobile belts. In The crust of the Earth: a symposium., Geol. Soc. America, Sp. Paper 62: 409-430

SANTOS, E.J. dos - 1971 - Síntese da geologia precambriana da folha Arcoverde. SUDENE, Div. Geol., 20 pp. (inédito)

WALTON, M. - 1955 - The emplacement of "granite". Am. J. Sci., 253: 1-18

WINKLER, H. G. F. - 1974 - The Petrogenesis of Metamorphic Rocks. Springer-Verlag New York Inc. 